Jurnal Wacana Kesehatan

Volume 5, Nomor 1, Juli 2020

e-ISSN 2544-6251

\title{
HUBUNGAN KOMPETENSI (PENGARAHAN) KEPALA RUANG TERHADAP KINERJA PERAWAT PELAKSANA DI RUANG RAWAT INAP RSUD Dr. ADJIDARMO KABUPATEN LEBAK
}

\section{RELATION SUPERVISORS' MANAGERIAL COMPETENCIES (DIRECTION) OF IMPLEMENTER NURSES' IN IMPLEMENTING NURSING CARE}

\author{
Ika Purwanto $^{1}$, I Dewa Agung Gde Fanji Pradiptha ${ }^{2}$ \\ ${ }^{1}$ Akademi Keperawatan Yatna Yuana Lebak \\ ${ }^{2}$ STIKES Bina Usada Bali \\ E-mail: ikapurwantoskp@gmail.com
}

\begin{abstract}
ABSTRAK
Kompetensi adalah kemampuan individu untuk melaksanakan suatu pekerjaan dengan benar dan memiliki ke unggulan menyangkut pengetahuan, keahlian dan sikap, kepala ruangan menjadi Frontline di ruangan untuk mengarahkan perawat pelaksana agar kinerja perawat pelaksana baik dan lebih ditingkatkan. Tujuan dari penelitian ini adalah Teridentifikasinya hubungan kompetensi kepala ruang terhadap kinerja perawat pelaksana dalam menerapkan asuhan keperawatan di Ruang Rawat Inap RSUD Dr. Adjidarmo Kabupaten Lebak, Penelitian ini menggunakan desain penelitian kuantitatif dengan studi korelasi, dengan pendekatan deskriptif cross sectional. Jumlah sampel 132 perawat pelaksana di 10 ruang rawat inap. Proses analisa data dengan SPSS 22 untuk menguji variable. Hasil penelitian diperoleh nilai P Value $=0.04, \mathrm{OR}=2.314$, pada tingkat kepercayaan 95\% (alpha 5\%). Kesimpulan menunjukkan ada hubungan kompetensi ( pengarahan) kepala ruang terhadap kinerja perawat pelaksana.
\end{abstract}

Kata Kunci: Kompetensi Kepala ruang, Pengarahan, Kinerja Perawat Pelaksana

\begin{abstract}
Competence is the ability of individuals to carry out a job correctly and has superiority regarding knowledge, skills and attitudes, supervisors' managerial becomes Frontline in the room to direct the executive nurse so that the performance of the implementer nurses' is better and more improved. The purpose of this study is the Identification of the Relatin of supervisors' managerial Competence to the Performance of the implementer nurses' in Implementing Nursing Care in the Inpatient Room of RSUD Dr. Adjidarmo Lebak, this study uses a quantitative research design with a correlation study, with a cross sectional descriptive approach. The number of samples was 132 nurses in 10 inpatient rooms. Data analysis process with SPSS 22 to test the variables. The results obtained by the value of P Value $=0.04, \mathrm{OR}=2.314$, at a confidence level of $95 \%$ (alpha 5\%), the conclusion shows that there is a relationship between the competence (direction) of the head of the room on the performance of the implementing nurse.
\end{abstract}

Keywords: Supervisors' Managerial Competencies, Direction, Performance of Nurse Implementer 


\section{PENDAHULUAN}

Rumah sakit merupakan lembaga pelayanan kesehatan yang melaksanakan pelayanan kesehatan secara paripurna yang menyediakan pelayanan rawat inap, rawat jalan, dan rawat darurat (Permenkes No. 147 Tahun 2010), sedangkan menurut AHA (American Hospital Association), rumah sakit adalah suatu instansi dengan peran utamanya adalah memberikan pelayanan kepada pasien ${ }^{1}$. Rumah sakit bagian dari tatanan yang memberikan jasa pelayanan kesehatan wajib mengadakan berbagai jenis pelayanan kesehatan yang berkualitas, lembaga pelayanan kesehatan yang elusif (kompleks), padat (karya, pakar, modal) ${ }^{2}$.

Manajemen keperawatan menggambarkan serangkaian penerapan pelayanan keperawatan yang dilakukan oleh praktisi keperawatan dalam memberikan asuhan keperawatan, rasa aman kepada pasien/ keluarga serta masyarakat ${ }^{3}$. Pengaturan yang berintegrasi dari sumber keperawatan dengan mengaplikasikan prosedur manajemen dalam mencapai target obyektivitas asuhan keperawatan dan pelayanan keperawatan merupakan suatu langkah manajemen dalam keperawatan ${ }^{2}$. Proses manajemen terdiri 5 fase yaitu: perencanaan (planning), organisasi (organizing),ketenagaan (staffing), pengarahan (directing) dan pengawasan (controlling) menggambarkan satu siklus yang saling berhubungan, Agar mampu mengaplikasikan manajemen keperawatan diruang rawat inap dibutuhkan kepala ruang yang memenuhi standar.
Seorang manajer diharapkan mampu mengelola pelayanan keperawatan diruang rawat inap dengan menggunakan pendekatan manajemen keperawatan seperti yang disebutkan diatas lima fase proses manajemen ${ }^{4}$.

Barometer potret sebuah Rumah Sakit di mata masyarakat adalah pelayanan keperawatan merupakan bagian dari dalam sistem pelayanan kesehatan, maka rumah sakit wajib untuk menjaga mutu pelayanan, yang pada akhirnya menuntut adanya profesionalisme perawat pelaksanan maupun pengelola untuk mengatur kegiatan dalam pemberian asuhan keperawatan kepada pasien. Manajer dengan kemampuan dan ketrampilan yang memadai akan memberikan kontribusi yang optimal dalam mewujudkan pelayanan kesehatan yang bermutu akan terwujud apabila sistem pemberian asuhan keperawatan yang digunakan mendukung terbentuknya praktik keperawatan profesional dan berpedoman pada standar yang telah ditetapkan ${ }^{5}$.

Kepala ruangan termasuk kedalam tingkatan manajer operasional, yang merupakan jabatan strategis dikarenakan secara manjerial dapat menentukan keberhasilan pelayanan keperawatan yang diberikan, seorang kepala ruang yang memimpin langsung dan mengendalikan sumber daya pada bagian perawatan dalam rangka mewujudkan kualitas jasa keperawatan yang berkualitas. Mempunyai keahlian secara tehnik, mampu berkomunikasi secara efektif dan mampu memanajemen waktu dengan efisien ${ }^{6}$. 
Kompetensi kepemimpinan yang tidak tepat kepada pegawai, bisa menjatuhkan motivasi, kinerja dan kepuasan kerja, bahwa kompetensi kepemimpinan berdampak kepada kinerja $(t=2,878>1,96)$, kinerja dapat dipengaruhi oleh tiga faktor yaitu faktor psikologis, organisasi dan individu ${ }^{7}$.Faktor individu diantaranya kemampuan, keterampilan dan pengalaman kerja bagi manajer keperawatan dan pimpinan perlu dibuat suatu kebijakan terkait dengan persyaratan untuk menjadi kepala ruangan adalah perawat dengan pengalaman kerja $>5$ tahun dan berusia 45 tahun ke bawah, tingkat sosial dan demografi ${ }^{8}$.

Identifikasi yang di dapat pada saat survey dengan angket sederhana kepada 10 kepala ruangan untuk menilai efektifitas kepemimpinan dan manajemen, didapat data untuk efektifitas kepemimpinan kepala ruangan sebesar $83.4 \%$. Sedangkan efektifitas manajemen dari fungsi monitoring hanya $65 \%$. Dalam studi pendahuluan fungsi manajemen ini hanya dinilai dari segi kepala ruangan, untuk melihat (tilik diri) apakah hal-hal yang baik dari kepemimpinan dan fungsi manajemen teridentifikasi dengan baik, baik dari segi proses sampai dengan pada evaluasi, yang pada akhirnya apakah fungsi manajemen akan berpengaruh pada kinerja pegawai dalam hal ini perawat ketika melakukan asuhan keperawatan.

Evaluasi kinerja sumber daya manusia keperawatan RSUD Dr. Adjidarmo yang penulis dapat dari kepala bidang keperawatan pada tahun
2016, yang dilaksanakan secara periodik sebanyak 895 berkas perawat/ bidan dengan frekuensi 2 kali/tahun. Ada 23 perawat yang dilakukan pembinaan. Diantaranya dengan permasalahan kedisiplinan dalam bekerja, pelanggaran etika keperawatan dan permasalahan pribadi perawat/bidan yang berimbas dalam kinerja pelayanan. Terkait penilaian kinerja perawat pelaksana belum terkaji secara rinci berapa jumlah perawat dengan kinerja baik atau yang kurang baik sehingga perlu pembinaan. Data yang didapat dari wawancara dan observasi pada bulan desember 2019 kepada 10 kepala ruang mengatakan $100 \%$ perawat belum mengikuti pelatihan manajemen bangsal. Sejalan dengan pernyataan yang dikemukakan oleh kepala bidang keperawatan bahwa yang sudah mendapatkan pelatihan manajemen bangsal seluruh kepala dan wakil kepala ruangan. Sejalan dengan wawancara terhadap kepala bidang keperawatan, pelatihan kompetensi kepemimpinan belum dilaksanakan dan (SPO) standar operasional prosedur peran dan fungsi kepala ruang dalam tinjauan dan perumusan, maka pengembangan kompetensi kepemimpinan dalam rangka meningkatkan kinerja perawat pelaksana belum dapat dijelaskan.

\section{ANAIL (Americans Nursing Association Institute} Leadership) tahun 2013 bahwa kompetensi kepemimpinan dibagi menjadi tiga yaitu adalah memimpin diri sendiri, orang lain dan organisasi. Standar kompetensi kepemimpinan Ners adalah mengadvokasi dan bertindak dalam menciptakan 
lingkungan kerja yang positif, menyelesaikan konflik dengan cara pendekatan manjemen keperawatan serta memperhatikan perilaku organisasi, memberikan kontribusi untuk kepemimpinan tim dengan memperkuat tujuan sehingga menimbulkan sikap saling menghargai dan percaya diri, memprioritaskan tugas dan mengelola waktu secara efektif, memberikan kontribusi pada hasil review dan modifikasi kebijakan dan prosedur organisasi terbaru, berperan serta aktif memberikan evaluasi dan tindak lanjut kepada organisasi di lingkungan kerja. Sedangkan standard kompetensi kepemimpinan bagi perawat ahli madya: berkontribusi dalam menciptakan lingkungan kerja yang kondusif, menguasai manajemen penanganan konflik, konsisten membantu kepemimpinan dalam tim untuk meningkatkan percaya diri, rasa saling menghargai dan hormat antar anggota tim ${ }^{9}$.

Analisis tanggung jawab kepala ruang: Manajemen mutu pelayanan : agar bisa dirasakan langsung oleh pasien, keluarga dan masyarakat serta manjamin kualitas pelayanan keperawatan dan memuaskan semua pihak maka dalam melaksanakan asuhan keperawatan profesional harus berdasarkan pada kaidah ilmiah dan etika profesi. Ketenagaan: merekognisi dan merencanakan kebutuhan tenaga keperawatan dan non keperawatan di unitnya serta memberdayakan tenaga yang sudah ada. Manajemen finansial: merencankan kebutuhan logistik keperawatan (pengadaan dan pemanfaatan alat kesehatan dan material kesehatan) ${ }^{3}$. Agar tujuan keperawatan tercapai maka mutu pelayanan, harus di dukung oleh kompetensi kepemimpinan. Keterampilan seorang kepala ruang dalam mempengaruhi staf perawat lain dibawah pengawasan, dalam pembagian tugas dan tanggung jawab ${ }^{10}$.

Nilai persepsi pasien terhadap kualitas ASKEP (asuhan keperawatan) di RSUD Dr.Adjidarmo kabupaten Lebak tahun 2016 sebesar 91 \%. Dari ke 10 ruangan yang dilakukan evaluasi, hampir seluruh ruangan dengan capaian standar pelayanan minimal (SPM) sudah ada pada kategori baik.

Fenomena yang ada belum menunjukkan seberapa baik kinerja perawat dimana perawat belum mampu memberikan pelayanan keperawatan yang terbaik kepada pasien, karena hasil evaluasi menunjukan persepsi pasien akan mutu asuhan keperawatan cukup baik, apakah ada kaitan dengan kepemimpinan dalam hal ini kompetensi kepala ruang dalam menerapkan fungsi manajemen sehingga kinerja perawat pelaksana dinilai baik.

\section{METODE}

Penelitian ini dilaksanakan di ruang rawat inap RSUD. Dr. Adjidarmo Lebak, dengan Populasi dalam penelitian ini perawat di 10 ruang rawat inap dengan total 196 perawat, dengan jumlah sampel 132 perawat. Pengambilan sampel tersebut akan diambil secara proporsional 
berdasarkan distribusi di setiap ruang rawat yang sesuai dengan kriteria inklusi, yaitu perawat di ruang rawat inap, bersedia menjadi responden, tidak sedang cuti / pendidikan, lama bekerja lebih dari satu tahun, Data yang didapat dikumpulkan dari sumber data primer yaitu data yang diperoleh melalui wawancara langsung kepada perawat pelaksana dengan kuesioner ${ }^{11}$. Uji validitas dilakukan pada 30 perawat pelaksana di RSUD Berkah Pandeglang. Hasil uji reliabilitas instrument pada penelitian ini didapatkan nilai $r$ $\alpha$ cronbach's sebesar 0,979 pada instrument fungsi manajemen, dan nilai $\mathrm{r} \alpha$ kinerja sebesar 0.972. Kemudian nilai tersebut dibandingkan dengan nilai $r$ table $(0,374)$ dari perbandingan tersebut didapatkan nilai $r \alpha$ cronbach's $\geq$ nilai $\mathrm{r}$ table, Analisis data untuk menganalisis data univariat dan data bivariat. dilakukan dengan menggunakan SPSS 22.

\section{HASIL}

\section{Tabel 1}

Distribusi responden berdasarkan jenis kelamin, umur, tingkat pendidikan, status kepegawaian dan lama kerja, di ruang rawat inap RSUD dr. Adjidarmo $(\mathbf{n}=\mathbf{1 3 2})$

\begin{tabular}{lcc}
\hline \multirow{2}{*}{ Karakteristik } & \multicolumn{2}{c}{ Frekuensi } \\
\cline { 2 - 3 } & Jumlah & Presentase \\
\hline Jenis kelamin & & \\
Laki-laki & 33 & 25 \\
Perempuan & 99 & 75 \\
& & \\
Umur & & \\
$<30$ tahun & 43 & 43 \\
$31-40$ tahun & 85 & 85 \\
$>40$ tahun & 4 & 4
\end{tabular}

\section{Tingkat \\ Pendidikan}

D III 112

Keperawatan

Ners ( Profesi)

20 84.8

15.2

\section{Status \\ Kepegawaian \\ ASN} 16

Non ASN

116

12.1

87.9

\section{Lama Kerja}

3- 5 tahun

6-10 tahun

22

16.7

$>11$ tahun

92

69.7

$18 \quad 13.6$

Bersarkan tabel 1 jenis kelamin responden terbanyak perempuan sebanyak $75 \%$, sedangkan laki-laki sebanyak $33 \%$. Distribusi umur responden dibagi menjadi tiga kategori berdasarkan pada hasil analisis nilai median 31 tahun. Dari kategori tersebut menunjukkan umur responden 31-40 tahun paling banyak yaitu 64.4 $\%$. Distribusi tingkat pendidikan responden yang paling banyak adalah responden dengan tingkat pendidikan D III Keperawatan sebanyak $84.8 \%$, S1+ Ners sebanyak $15.2 \%$. Distribusi status perkawinan responden yang paling banyak adalah responden yang kawin sebanyak $86.4 \%$, sedangkan yang belum kawin sebanyak $13.6 \%$. Distribusi status kepegawain responden yang paling banyak adalalah dengan status Non ASN $87.9 \%$, sedangkan yang ASN sebanyak $12.1 \%$. Distribusi lama kerja responden dibagi menjadi tiga kategori berdasarkan hasil analisis median 7.5 tahun. Dari kategori tersebut menunjukkan lama kerja responden 6- 10 tahun sebanyak 69,7 $\%,>11$ tahun sebanyak $13.6 \%$, sedangkan lama kerja responden 3-5 tahun sebanyak $16.7 \%$. 
Tabel 2

Karakteristik responden berdasarkan variable penelitian kompetensi kepala ruang (Fungsi Pengarahan) $(n=132)$

\begin{tabular}{lcc}
\hline \multicolumn{1}{c}{ Variabel } & Frekuensi & Persentase \\
\hline Kurang & 51 & 38.6 \\
Baik & 81 & 61.4 \\
Jumlah & 132 & 100 \\
\hline
\end{tabular}

Berdasarkan tabel 2 diatas dapat dilihat bahwa sebanyak $81(61.4 \%)$ perawat mengatakan kepala ruangan sudah memberikan pengarahan yang baik dan 51(38.6\%) perawat mengatakan masih kurang.

Tabel 3

\section{Karakteristik Responden berdasarakan varibael penelitian Kinerja Perawat Pelaksana $(\mathbf{n}=132)$}

\begin{tabular}{llcc}
\hline Variabel & & $\begin{array}{c}\text { Frek } \\
\text { uensi }\end{array}$ & Persentase \\
\hline \multirow{2}{*}{ Pengkajian } & Kurang & 32 & 24.2 \\
& Baik & 100 & 75.8 \\
& Kurang & 36 & 27.3 \\
Diagnosa & Baik & 96 & 72.7 \\
& & & \\
Intervensi & Kurang & 39 & 29.5 \\
& Baik & 93 & 70.5 \\
Implement & Kurang & 39 & 29.5 \\
asi & Baik & 93 & 70.5 \\
& & & \\
& & & \\
Evaluasi & Kurang & 44 & 33.3 \\
& Baik & 88 & 66.7 \\
& Jumlah & 132 & 100 \\
\hline
\end{tabular}

Tabel 3 tentang Variabel kinerja parawat, dalam melakukan asuhan keperawatan, pengkajian baik sedangkan nilai terendah pada intervensi sebesar 10.58 . dengan 100 (75.8\%), kurang 32 (24.2\%), merumuskan diagnosa baik 96 (72.7\%), kurang $36(27.3 \%)$, menyusun intervensi dan melakukan implementasi baik 93 (70,5\%), kurang 39 (29.5\%), dan evaluasi menjadi variable dengan kinerja baik hanya 88 (6.7\%), dan 44 (33.3\%) kurang.

Tabel 4

Distribusi Frekuensi Kompetensi Kepala Ruang (Fungsi Pengarahan), Kinerja perawat Pelaksana. $(\mathbf{n}=\mathbf{1 3 2})$

\begin{tabular}{llll}
\hline No & Variabel & Mean & $\begin{array}{l}\text { Std. } \\
\text { Deviasi }\end{array}$ \\
\hline
\end{tabular}

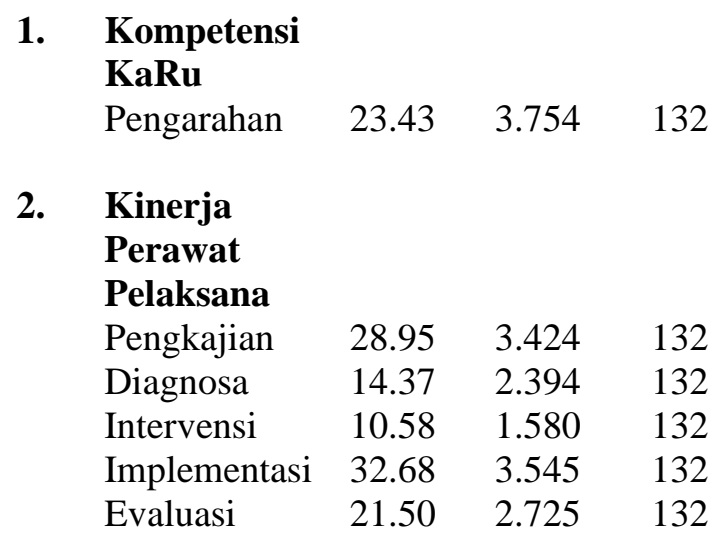

Tabel 4 menunjukkan bahwa dari 132 responden perawat pelaksana di peroleh nilai rata-rata atau mean dari variabel kompetensi kepala ruang dalam melakukan pengarahan adalah 23.43 dengan standar deviasi 3.754, untuk variabel kinerja perawat pelaksana nilai mean tertinggi pada indikator implementasi sebesar 32.68, 
Tabel 5

Distribusi Responden Menurut Kompetensi KaRu (Pengarahan) dan Kinerja Perawat Pelaksana $(\mathbf{n = 1 3 2})$

\begin{tabular}{|c|c|c|c|c|c|c|c|c|c|}
\hline \multirow{3}{*}{\multicolumn{2}{|c|}{$\begin{array}{l}\text { Kinerja Perawat } \\
\text { Pelaksana }\end{array}$}} & \multicolumn{4}{|c|}{$\begin{array}{l}\text { Kompetensi KaRu } \\
\text { (Pengarahan) }\end{array}$} & \multirow{2}{*}{\multicolumn{2}{|c|}{ Total }} & \multirow{3}{*}{$\begin{array}{l}\text { OR } \\
(95 \% \\
\text { CI })\end{array}$} & \multirow{3}{*}{$\begin{array}{l}\mathbf{P} \\
\text { Value }\end{array}$} \\
\hline & & \multicolumn{2}{|c|}{ Kurang } & \multicolumn{2}{|c|}{ Baik } & & & & \\
\hline & & $\mathbf{n}$ & $\%$ & $\mathbf{n}$ & $\%$ & $\mathbf{n}$ & $\%$ & & \\
\hline \multirow{3}{*}{ Pengkajian } & Kurang & 19 & 37.3 & 32 & 62.7 & 51 & 100 & \multirow{3}{*}{$\begin{array}{l}3.106 \\
1.4-7\end{array}$} & \multirow{3}{*}{0.010} \\
\hline & Baik & 13 & 16.0 & 68 & 84.0 & 81 & 100 & & \\
\hline & Jumlah & 32 & 24.2 & 100 & 75.8 & 132 & 100 & & \\
\hline \multirow{3}{*}{ Diagnosa } & Kurang & 21 & 41.2 & 30 & 58.8 & 51 & 100 & 3.080 & \multirow{3}{*}{0.008} \\
\hline & Baik & 15 & 18.5 & 66 & 81.5 & 81 & 100 & $1.4-$ & \\
\hline & Jumlah & 36 & 27.3 & 96 & 72.7 & 132 & 100 & 6.8 & \\
\hline \multirow{3}{*}{ Intervensi } & Kurang & 20 & 39.2 & 31 & 60.8 & 51 & 100 & \multirow{3}{*}{$\begin{array}{l}2.105 \\
1-4.5\end{array}$} & \multirow{3}{*}{0.082} \\
\hline & Baik & 19 & 23.5 & 62 & 76.5 & 81 & 100 & & \\
\hline & Jumlah & 39 & 29.5 & 93 & 70.5 & 132 & 100 & & \\
\hline \multirow{3}{*}{ Implementasi } & Kurang & 21 & 41.2 & 30 & 58.8 & 51 & 100 & 2.450 & \multirow{3}{*}{0.033} \\
\hline & Baik & 18 & 22.2 & 63 & 77.8 & 81 & 100 & $1.1-$ & \\
\hline & Jumlah & 39 & 29.5 & 93 & 70.5 & 132 & 100 & 5.2 & \\
\hline \multirow{3}{*}{ Evaluasi } & Kurang & 25 & 49.0 & 26 & 51.0 & 51 & 100 & 3.138 & \multirow{3}{*}{0.004} \\
\hline & Baik & 19 & 23.5 & 62 & 76.5 & 81 & 100 & $1.5-$ & \\
\hline & Jumlah & 44 & 33.3 & 88 & 66.7 & 132 & 100 & 6.7 & \\
\hline
\end{tabular}

Tabel 5 menunjukkan bahwa responden dengan kinerja baik diberikan pengarahan baik dalam melakukan pengkajian oleh kepala ruangan sebanyak 68(84\%), diagnosa 66(81\%), intervensi 62(76.5\%), implementasi 63(77.8\%), evaluasi $62(76.5 \%)$ dan perawat pelaksana dengan kinerja baik mendapatkan arahan yang kurang sebanyak 13(16.0\%), diagnosa 15(18.5\%), intervensi 19(23.5\%), implementasi 18(22.2), evaluasi 19(23.5\%). Sementara perawat pelaksana yang kinerjanya kurang diberikan pengarahan yang baik saat melakukan pengkajian sebanyak $32(62.7 \%)$, diagnosa 30(58.8\%), intervensi $31(60.8 \%)$, implementasi 30(58.8\%), evaluasi $26(51.0 \%)$ dan untuk hasil pengarahan kurang sebanyak 19(37.3\%), diagnosa 21(41.2\%), intervensi 20(39.2\%), implementasi 21(41.2\%), dan evaluasi 25(49\%).

Dari hasil uji statistik yang dilkukan diperoleh untuk pengkajian, diagnosa, implementasi dan evaluasi nilai P Value $=0.010,0.008,0.033,0.004$ sehingga dapat disimpulkan bahwa pada tingkat kepercayaan 95\% (alpha 5\%) adanya hubungan antara kompetensi kepala ruang dalam melakukan arahan dengan kinerja perawat pelaksana dalam melakukan pengkajian, menyusun diagnosa, melakukan tindakan keperawatan dan mengevaluasi, sedangkan pada 
variabel intervensi dari hasil uji statistik di dapat nilai $\mathrm{P}$ value 0.082 , artinya tidak ada pengaruh atau hubungan antara kompetensi kepala ruang dalam melakukan pengarahan dengan kinerja perawat dalam menyusun intervensi

Tabel 6

\section{Hubungan Kompetensi Kepala Ruang dalam melakukan pengarahan dengan Kinerja Perawat Pelaksana ( $\mathbf{n}=132)$}

\begin{tabular}{|c|c|c|c|c|c|c|c|c|c|}
\hline \multirow{3}{*}{ Variabe } & & \multicolumn{4}{|c|}{$\begin{array}{c}\text { Kinerja Perawat } \\
\text { Pelaksana }\end{array}$} & \multirow{2}{*}{\multicolumn{2}{|c|}{ Total }} & \multirow{3}{*}{$\begin{array}{c}\text { OR } \\
(\mathbf{9 5 \%} \\
\text { CI })\end{array}$} & \multirow{3}{*}{$\begin{array}{c}\mathbf{P} \\
\text { Valu } \\
\boldsymbol{e}\end{array}$} \\
\hline & & \multicolumn{2}{|c|}{ Kurang } & \multicolumn{2}{|c|}{ Baik } & & & & \\
\hline & & $\mathbf{n}$ & $\%$ & $\mathrm{n}$ & $\%$ & $\mathbf{n}$ & $\%$ & & \\
\hline Kompetensi & Kurang & 22 & 43.1 & 29 & 56.9 & 51 & 100 & & \\
\hline KaRu & Baik & 20 & 24.7 & 61 & 75.3 & 81 & 100 & 2.314 & 0.04 \\
\hline (Pengarahan) & Jumlah & 42 & 31.8 & 90 & 68.2 & 132 & 100 & & \\
\hline
\end{tabular}

Tabel 6 menunjukkan responden dengan diberikan pengarahan oleh kepala ruang baik memiliki kinerja yang baik sebanyak 61(75.3\%) perawat, pengarahan oleh kepala ruang baik dengan kinerja perawat pelaksana kurang 20 (24.7\%), untuk pengarahan kurang oleh kepala ruang kepada perawat pelaksana dengan kinerja baik sebanyak 29(56.9\%). Sementara kinerja perawat pelaksana kurang dengan pengarahan yang kurang sebanyak 22(43.1\%).

Dari hasil uji statistik yang dilkukan diperoleh nilai $\mathrm{P}$ Value $=0.04$ sehingga dapat disimpulkan bahwa pada tingkat kepercayaan 95\% (alpha 5\%) adanya hubungan antara kompetensi kepala ruang dalam melakukan arahan dengan kinerja perawat pelaksana dalam melakukan asuhan keperawatan.

\section{PEMBAHASAN}

Perawat manajer memainkan peran penting dalam menciptakan lingkungan kerja yang sehat dan melibatkan staff perawat dalam pengaturan di ruangan $^{12}$. Maka dari itu diperlukan manager (kepala ruang) yang memiliki kompetensi, kompetensi merupakan kemampuan menjalankan tugas atau pekerjaan dengan dilandasi oleh pengetahuan, keterampilan, dan didukung oleh sikap yang menjadi karakteristik individu. sumber daya manusia adalah pegawai yang siap, mampu, dan siaga dalam mencapai tujuan-tujuan organisasi ${ }^{13}$. Tidak ada hubungan yang signifikan antara kompetensi berdasarkan pengetahuan dalam menyusun perencanaan strategis yang merupakan bagian indikator dari fungsi manajemen. Ini terjadi karena perbedaan variabel kompetensi yang diteliti berbeda begitupun dengan instrument yang dipakai oleh peneliti ${ }^{14}$.

Hasil analisis bivariat menunjukan ada hubungan antara kompetensi kepala ruang dalam menerapkan fungsi pengarahan terhadap kinerja perawat dalam menerapkan asuhan keperawatan di ruang rawat inap RSUD Dr. Adjidarmo dengan nilai $\mathrm{P}$ Value $=0.04$ dan nilai Odd Ratio $(\mathrm{OR})=$ 2.314, berarti perawat pelaksana yang 
memepersepsikan fungsi pengarahan kepala ruang baik mempeunyai peluang 2.314 kali lebih besar untuk merasa baik dengan pekerjaannya disbanding perawat pelaksana yang mempersepsikan kurang baik. Hal ini mengidentifikasikan bahwa semakin baik persepsi perawat pelaksana terhadap pelaksanaan fungsi pengarahan kepada ruangan maka akan semakin besar kemungkinan perawat pelaksana memilii kinerja yang baik terhadap pekerjaaanya, begitu juga sebaliknya. Terkait pelaksanaan fungsi manajemen pengarahan kepala ruang dengan kinerja perawat dengan nilai $\mathrm{P}$ Value $=$ 0.04, hal ini dapat menjadi landasan bagi rumah sakit untuk meningkatkan pelaksanaan fungsi pengarahan yang memang sudah dinilai baik oleh perawat pelaksana lebih tinggi lagi ${ }^{15}$.

Pelaksanaan fungsi pengarahan sesuai standar yang dilaksanakan secara berkesinambungan akan meningkatan kemampuan perawat dalam memberikan pelayanan keperawatan. Hal ini didukung oleh teori Swansburg mengatakan pengarahan yang efektif akan meningkatkan dukungan perawat untuk mencapai tujuan manajemen keperawatan dan tujuan asuhan keperawatan ${ }^{16}$.

Upaya yang dapat dilakukan oleh institusi dalam meningkatkan kinerja karyawan adalah dengan melihat detail aspek-aspek yang menghambat karyawan dalam bekerja, baik yang meliputi struktur maupun proses. Implementasi fungsi pengarahan oleh kepala ruangan harus dilakukan secara sistematis dan berkesinambungan sehingga tujuan dapat tercapai secara optimal.
Arahan yang baik dari kepala ruangan dapat menciptakan iklim kerja yang baik, dan kinerja perawat akan meningkat jika kepala ruangan sering memberikan motivasi, dan memberikan bimbingan kepada perawat secara berkelanjutan sehingga berdampak pada terjalinnya komunikasi yang efektif antara perawat pelaksana dan kepala ruangan sehingga kinerja perawat dalam memberikan asuhan keperawatan semakin baik.

\section{KESIMPULAN}

Ada hubungan kompetensi kepala ruang dalam melaksanakan pengarahan terhadap kinerja perawat pelaksana dalam menerapkan asuhan keperawatan di ruang rawat inap Secara detail dapat dijelaskan responden dengan kinerja baik diberikan pengarahan baik dalam melakukan pengkajian oleh kepala ruangan sebanyak 68(84\%), diagnose 66(81\%), intervensi $62(76.5 \%)$, implementasi $63(77.8 \%)$, evaluasi $62(76.5 \%)$ dan perawat pelaksana dengan kinerja baik mendapatkan arahan yang kurang sebanyak 13(16.0\%), diagnose 15(18.5\%), intervensi 19(23.5\%), implementasi 18(22.2), evaluasi 19(23.5\%). Sementara perawat pelaksana yang kinerjanya kurang diberikan pengarahan yang baik saat melakukan pengkajian sebanyak $32(62.7 \%)$, diagnose 30(58.8\%), intervensi $31(60.8 \%)$, implementasi 30(58.8\%), evaluasi 26(51.0\%) dan untuk hasil pengarahan kurang sebanyak 19(37.3\%), diagnose 21(41.2\%), intervensi 20(39.2\%), implementasi 21(41.2\%), dan evaluasi $25(49 \%)$. 


\section{DAFTAR PUSTAKA}

1. Wibowo. (2007). Manajemen Kinerja. Jakarta : PT. Rajagrafindo Persada

2. Haryanti, Shinta. (2013). Pengaruh Gaya Kepemimpinan, Budaya organisasi, dan Kompetensi Karyawan Terhadap Kinerja dengan Komitmen Organisasional sebagai Variabel Mediasi. Jurnal Bisnis dan Manajemen. Vol 15. No.1. http://Jurnal.uns.ac.id/jbm/article/view/411

2. Diakses 20 Februari 2020

3. Kurniadi A. (2013). Manajemen Keperawatan dan Prosfektifnya (Teori, Konsep dan Aplikasi). Jakarta: Badan Penerbit Fakultas Kedokteran Universitas Indonesia

4. Triwibowo, C. (2013). Manajemen Pelayanan Keperawatan di Rumah Sakit. Jakarta : Trans Info Media

5. Sri Wahyuni,(2007). Analisis Kompetensi Kepala Ruang Dalam Pelaksanaan Standar Manajemen Pelayanan Keperawatan Dan Pengaruhnya Terhadap Kinerja Perawat Dalam Mengimplementasikan Model Praktik Keperawatan Profesional Di Instalasi Rawat Inap Rsud Banjarnegara. Tesis, dipublikasikan, Semarang. Universitas Diponegoro Semarang

6. Simamora, R. (2012). Buku Ajar Manajemen Keperawatan. Jakarta : EGC

7. Sudariani, Widhi P. (2016). Model Kompetensi Kepemmpinan Kepala Ruang Meningkatkan Motivasi dan Kinerja Perawat Pelaksana.Jurnal Ners. Vol.11 No.2 176-185.

http://garuda.ristekbrin.go.id/author/view/1 357802. Tanggal akses 9 Maret 2020.

8. Nursalam. (2015). Manajemen Keperawatan Aplikasi dalam Praktik Keperawatan Profesional. . Jakarta: Salemba Medika

9. PPNI, 2012. Standar praktek keperawatan, perawat professional, Jakarta.
10. Maryanto, dkk. (2013). Hubungan Gaya Kepemimpinan Kepala Ruang dengan Kepuasan Perawat di Rumah Sakit Swasta di Demak. Journal Managemen Keperawatan, 1 (2). 146-153. http://brilian.unimus.ac.id/ojsunimus/index. php/jmkarticel/view/0111/1060. Tanggal akses 20 Desember 2019.

11. Nursalam. (2017). Metodologi Penelitian Ilmu Keperawatan Pendekatan Praktis, edisi 4. Jakarta: Salemba Medika

12. Chase, Linda K, (2010)."Nurse Manager Competencies." $\mathrm{PhD}$ (Doctor of Philosophy) thesis, University of Iowa, 2010. http://ir.uiowa.edu/etd/2681.

13. Sutrisno. 2012. Manajemen Sumber Daya Manusia, Jakarta: Kencana

14. Sukrang, Ake J, dkk. ( 2014). Hubungan Kompetensi Dengan Peran Kepala Ruangan Dalam Perencanaan Strategi Rumah Sakit Bidang Keperawatan Di RS Pemerintah di Kota Palu.//ute_romeo@yahoo.com.id.

15. Zulkaratrnain (2017). Analisis pelaksanaan Fungsi manajemen pengarahan kepala ruangan dengan kinerja perawat dalam menerapkan ASKEP di ruang rawat inap RSUD Bima tahun 2017. http://ejournal.mandalanursa.org/index.php/ JISIP/article/view/356/345. Tanggal akses 27 Februari 2020

16. Marquiz, Bessie. L \& Houston, Carol. 2010. Kepemimpinan dan Manajemen Keperawatan: teori \& aplikasi. Ed.4. Jakarta: EGC 